OPEN ACCESS

Edited by: Vicent Arbona,

Jaume I University, Spain

Reviewed by:

Jing Bo Jin,

Institute of Botany (CAS), China

Wan-Hsing Cheng,

Academia Sinica, Taiwan

*Correspondence.

Kai Shu

kshu@sicau.edu.cn

Wenyu Yang

mssiyangwy@sicau.edu.cn

tThese authors have contributed equally to this work

Specialty section:

This article was submitted to

Plant Abiotic Stress,

a section of the journal

Frontiers in Plant Science

Received: 22 May 2017

Accepted: 24 July 2017

Published: 10 August 2017

Citation:

Shu K, Qi Y, Chen F, Meng Y, Luo X,

Shuai H, Zhou W, Ding J, Du J,

Liu J, Yang F, Wang Q, Liu W,

Yong $T$, Wang $X$, Feng $Y$ and

Yang W (2017) Salt Stress Represses

Soybean Seed Germination by

Negatively Regulating

GA Biosynthesis While Positively

Mediating ABA Biosynthesis.

Front. Plant Sci. 8:1372.

doi: 10.3389/fp/s.2017.01372

\section{Salt Stress Represses Soybean Seed Germination by Negatively Regulating GA Biosynthesis While Positively Mediating ABA Biosynthesis}

Kai Shu ${ }^{1 \star t}$, Ying Qi't, Feng Chen ${ }^{1 \dagger}$, Yongjie Meng ${ }^{1}$, Xiaofeng Luo ${ }^{1}$, Haiwei Shuai', Wenguan Zhou' ${ }^{1}$, Jun Ding ${ }^{2}$, Junbo Du' ${ }^{1}$, Jiang Liu', Feng Yang ${ }^{1}$, Qiang Wang', Weiguo Liu' ${ }^{1}$, Taiwen Yong ${ }^{1}$, Xiaochun Wang ${ }^{1}$, Yuqi Feng ${ }^{2}$ and Wenyu Yang ${ }^{1 *}$

${ }^{1}$ Key Laboratory of Crop Ecophysiology and Farming System in Southwest China, Sichuan Engineering Research Center for Crop Strip Intercropping System, Institute of Ecological Agriculture, Sichuan Agricultural University, Chengdu, China, ${ }^{2}$ Key Laboratory of Analytical Chemistry for Biology and Medicine (Ministry of Education), Department of Chemistry, Wuhan University, Wuhan, China

Soybean is an important and staple oilseed crop worldwide. Salinity stress has adverse effects on soybean development periods, especially on seed germination and postgerminative growth. Improving seed germination and emergence will have positive effects under salt stress conditions on agricultural production. Here we report that $\mathrm{NaCl}$ delays soybean seed germination by negatively regulating gibberellin (GA) while positively mediating abscisic acid (ABA) biogenesis, which leads to a decrease in the GA/ABA ratio. This study suggests that fluridone (FLUN), an ABA biogenesis inhibitor, might be a potential plant growth regulator that can promote soybean seed germination under saline stress. Different soybean cultivars, which possessed distinct genetic backgrounds, showed a similar repressed phenotype during seed germination under exogenous $\mathrm{NaCl}$ application. Biochemical analysis revealed that $\mathrm{NaCl}$ treatment led to high MDA (malondialdehyde) level during germination and the post-germinative growth stages. Furthermore, catalase, superoxide dismutase, and peroxidase activities also changed after $\mathrm{NaCl}$ treatment. Subsequent quantitative Real-Time Polymerase Chain Reaction analysis showed that the transcription levels of ABA and GA biogenesis and signaling genes were altered after $\mathrm{NaCl}$ treatment. In line with this, phytohormone measurement also revealed that $\mathrm{NaCl}$ considerably down-regulated active $\mathrm{GA}_{1}, \mathrm{GA}_{3}$, and $\mathrm{GA}_{4}$ levels, whereas the $\mathrm{ABA}$ content was up-regulated; and therefore ratios, such as $\mathrm{GA}_{1} / \mathrm{ABA}, \mathrm{GA}_{3} / \mathrm{ABA}$, and $\mathrm{GA}_{4} / \mathrm{ABA}$, are decreased. Consistent with the hormonal quantification, FLUN partially rescued the delayed-germination phenotype caused by $\mathrm{NaCl}$-treatment. Altogether, these results demonstrate that $\mathrm{NaCl}$ stress inhibits soybean seed germination by decreasing the GA/ABA ratio, and that FLUN might be a potential plant growth regulator that could promote soybean seed germination under salinity stress.

Keywords: salinity, seed germination, abscisic acid, gibberellin, soybean 


\section{INTRODUCTION}

Salinity is one of the most important abiotic stresses in the world. It has adverse effects on almost all development stages during the plant life-cycle, including seed germination, seedling establishment and development, vegetative and reproductive growth, and crop survival and yield ( $\mathrm{Zhu}, 2016$ ). More than 45 million hectares of agricultural land have been damaged by salt worldwide, and $\mathrm{NaCl}$ stress is an important salinity stress (Munns and Tester, 2008). Over the past few decades, numerous studies have demonstrated that high soil salinity content significantly affects crop growth and development through many diverse pathways, including water stress, nutritional disorders, ion toxicity, oxidative stress, alterations to metabolic processes, cell membrane disorganization, and reduced cell expansion and division (Hasegawa et al., 2000; Munns, 2002; Zhu, 2002, 2016; Teige et al., 2004; Hanin et al., 2016). Therefore, the physiological and molecular mechanisms through which plants adapt to salt stress need further investigating and the results could lead to improvements in agricultural production worldwide, especially on saline land.

Soybean (Glycine max (L.) Merrill) is an important and staple oil crop worldwide, and is used as a plant oil and protein resource by humans. However, salinity stress has significantly decreased soybean yield by inhibiting seed germination and post-germinative growth. Several key regulators, including GmSALT3, GmMYB76, GmMYB92, GmMYB177, GmbZIP132, and $M i R 172 C$, have been documented, and their relatedmechanisms were investigated (Liao et al., 2008a,b; Guan et al., 2014; Wang et al., 2014; Kan et al., 2016; Li et al., 2016; Liu et al., 2016). High and uniform germination and emergence in the field are the key determinants of soybean yield, especially under salt stress conditions. Salinity represses soybean seed germination (Zhang et al., 2014; Kan et al., 2016), but the precise mechanisms underlying the inhibition effect of salt on soybean seed germination are only partially understood. Further, potential plant growth regulators need to be developed to promote soybean seed germination and emergence under salinity stress conditions.

Seed germination and post-germinative growth are critical stages during the plant life-cycle. The phytohormone abscisic acid (ABA) delays seed germination whereas gibberellin (GA) promotes this process, and both hormones are key regulators involved in seed germination processes (Finkelstein et al., 2008; Graeber et al., 2012; Nee et al., 2016; Shu et al., 2016b). Consistently, mutants with dysfunctional ABA and GA biosynthesis, and catabolic or signaling transduction pathways always show an altered germination phenotype. In Arabidopsis, the ABA biosynthesis mutants nced6, nced5, nced3, and aba2 (Seo et al., 2006; Frey et al., 2012), and ABA signaling mutants abi3 (Koornneef et al., 1989), abi4 (Shu et al., 2013), and abi5 (Piskurewicz et al., 2008) had a faster germination phenotype compared to wild type, whereas overexpression of Nicotiana $A B A 2$ or Arabidopsis ABI4 resulted in a delayed-germination phenotype (Frey et al., 1999; Shu et al., 2013). However, the seeds of GA-deficiency mutants, gal and ga2, failed to germinate unless there was an exogenous supply of GA (Lee et al., 2002; Shu et al., 2013), while the mutants that are defective in
GA2-oxidases (GA2ox), which deactivate bioactive GA, have a faster germination phenotype (Yamauchi et al., 2007). Further, the ratio between the levels of active GA/ABA is also a key determinant of seed germination (Shu et al., 2015, 2016b; Meng et al., 2016). Taken together, both ABA and GA levels, along with signaling play important roles in the regulation of seed germination.

Several abiotic stress conditions, including drought and salinity, lead to the up-regulation of ABA, which in turn elicits diverse adaptive responses in plants (Zhu, 2002, 2016). Osmotic stress-induced ABA accumulation is largely dependent on the activation of biosynthesis and the inhibition of degradation pathways (Zhu, 2002). Previous studies revealed that applying a salt treatment up-regulated the transcription levels of $Z E P$ and NCED genes, which encode the key enzymes involved in the ABA biosynthesis pathway (Xiong et al., 2002; Galle et al., 2013). Furthermore, some ABA biosynthetic mutants such as aba2 seeds germinate earlier than the wild type under salt stress conditions (Gonzalez-Guzman et al., 2002), and ABA2 transcript can also be upregulated by prolonged salt treatments (Lin et al., 2007). On the other hand, salinity negatively regulates GA biosynthesis during the seed germination and seedling development stages (Shakirova et al., 2003; Horvath et al., 2015; Zhang et al., 2016). A recent study showed that $\mathrm{ABA}$ and GA biosynthesis were also involved in seed heteromorphism in Suaeda salsa under salt stress conditions (Li et al., 2015). However, the relationship between salt stress and GA still needs further investigation, especially during the soybean seed germination processes.

This study shows that exogenous $\mathrm{NaCl}$ treatment inhibits soybean seed germination by mediating the ABA and GA biogenesis pathways, and importantly, our evidences demonstrate that an ABA biogenesis inhibitor, fluridone (FLUN), might be a potential plant growth regulator that could be used to enhance soybean seed germination under salinity stress conditions. The quantitative Real-Time Polymerase Chain Reaction (qRT-PCR) analysis revealed that the transcription levels of $\mathrm{ABA}$ and $\mathrm{GA}$ biogenesis genes were altered by $\mathrm{NaCl}$ application. Consistently, further phytohormone quantification revealed that $\mathrm{NaCl}$ remarkably down-regulated active $\mathrm{GA}_{1}$, $\mathrm{GA}_{3}$, and $\mathrm{GA}_{4}$ levels, whereas ABA content was up-regulated; and consequently the ratios for GA/ABA (including $\mathrm{GA}_{1} / \mathrm{ABA}$, $\mathrm{GA}_{3} / \mathrm{ABA}$, and $\mathrm{GA}_{4} / \mathrm{ABA}$ ) were significantly decreased. Taken together, it can be concluded that salt stress delays soybean seed germination by negatively regulating GA while positively mediating $\mathrm{ABA}$ biogenesis and that this consequently leads to a reduction in the GA/ABA ratios. Last but not least, FLUN can be used as a potential chemical to promote soybean seed germination and post-germinative growth under salinity stress conditions.

\section{RESULTS}

\section{Exogenous $\mathrm{NaCl}$ Application Delays Soybean Seed Germination}

We first tested the effect of exogenous $\mathrm{NaCl}$ treatment on soybean seed germination. The germination analysis showed 
that $\mathrm{NaCl}$ delays the seed germination processes in cultivar $\mathrm{ND}-12$ (Figures 1A,B). The germination rate of the $\mathrm{NaCl}$-treated soybean seeds was about two to three-fold less than the control (CK) during the germination processes (Figure 1B). Consistently, the analysis of several post-germinative growth parameters, including the length of radicle (Figure 1E) and the fresh weights of germinated seeds (Figure 1F), also supported that the delayed-germination phenotype was caused by the $\mathrm{NaCl}$ treatment (Figures 1A,B). To further confirm the inhibition effect of $\mathrm{NaCl}$ on soybean seed germination processes, we tested another cultivar, HD-19, which is genetically distinct from the ND-12 cultivar. The results revealed that $\mathrm{NaCl}$ treatment also inhibited HD-19 seed germination processes (Figures 1C,D), and the post-germinative growth analysis showed that postgerminative growth was also reduced by $\mathrm{NaCl}$ (Figures $\mathbf{1 G}, \mathbf{H}$ ). Exogenous $\mathrm{NaCl}$ application had a remarkable inhibitory effect on radicle length and the fresh weights of germinated seeds (Figures 1G,H).

Subsequently, we also analyzed the germination rate of the black soybean cultivar, C-103. The results revealed that $\mathrm{NaCl}$ application inhibited C-103 seed germination processes (Supplementary Figures S1A,B), and significantly reduced the radicle length and fresh weights of germinated seeds (Supplementary Figures S1C,D), which was similar to the analysis of HD-19 and ND-12 cultivars. These results demonstrated that exogenous $\mathrm{NaCl}$ treatment delays soybean seed germination processes.

\section{$\mathrm{NaCl}$ Application Caused Oxidative Stress during Soybean Seed Germination}

In order to test the cell oxidative status after treatment with exogenous $\mathrm{NaCl}$, oxidative stress parameters, including malondialdehyde (MDA) content, and catalase (CAT), superoxide dismutase (SOD), and peroxidase (POD) activities, were investigated during the seed germination processes. The results show that after exogenous $\mathrm{NaCl}$ treatment, the MDA content significantly increased, especially from $72 \mathrm{~h}$ to $94 \mathrm{~h}$ after imbibition (Figure 2A), which suggested that, during soybean seed germination and post-germinative growth, $\mathrm{NaCl}$ treatment increased the toxic stress in cells and inhibited both processes. Furthermore, the CAT, SOD, and POD activities also increased after $\mathrm{NaCl}$ application (Figures 2B-D). The increase in those enzymes suggested that $\mathrm{NaCl}$ treatment caused oxidative stress in cells during seed germination.

\section{$\mathrm{NaCl}$ Enhances ABA Biogenesis, but Impairs GA Biosynthesis}

Previous studies have demonstrated that ABA and GA play key roles in seed germination (Graeber et al., 2012; Shu et al., 2016b). Therefore, we further investigated the missing links between the inhibitory effect of $\mathrm{NaCl}$ on soybean seed germination and the effects on the GA and ABA pathways. Consequently, we explored the transcription patterns of ABA and GA biogenesis and signaling genes in soybean seeds during the imbibition process using a time-course analysis. Then we further analyzed
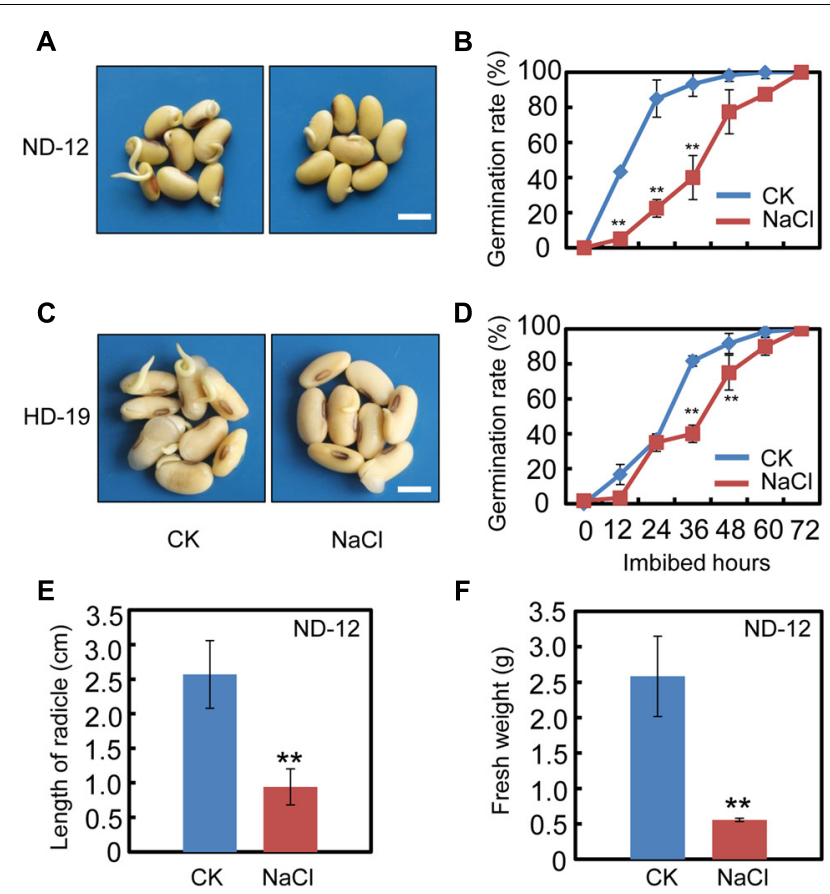

$\mathbf{F}$
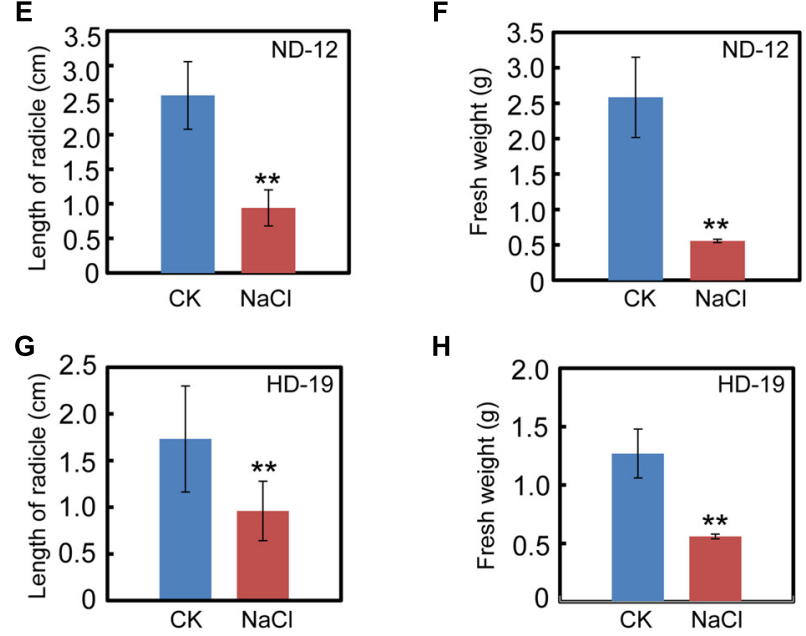

H

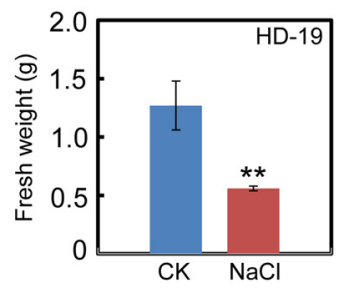

FIGURE 1 | NaCl inhibits soybean seed germination. Healthy soybean seeds (cultivars ND12 and HD19) were incubated on two layers of filter paper in Petri dishes. The concentration of $\mathrm{NaCl}$ used was $150 \mathrm{mM}$, and the equivalent ultrapure water was employed as control (CK). (A) The representative images (36 h after sowing) are shown for cultivar ND12. (B) Quantitative analysis of germination rates is shown for ND12. (C) The representative images (36 h after sowing) are shown for cultivar HD19. (D) Quantitative analysis of germination rates is shown for HD19. (E,F) Radicle length and fresh weight of germinated soybean seeds were measured for cultivar ND12. (G,H) Radicle length and fresh weight of germinated soybean seeds were measured for cultivar HD19. Bar $=10 \mathrm{~mm}$. The average percentages of four

repeats \pm standard error were shown. Student's $t$-test assay was employed for statistical analysis, and ** difference is significant at the 0.01 level.

the ABA and active GA content during seed imbibition after $\mathrm{NaCl}$ treatment.

The qRT-PCR results showed that the transcript level of the ABA biosynthesis genes: GmNCED9, GmNCED5, and GmAAO, were significantly up-regulated by $\mathrm{NaCl}$-treatment during seed imbibition compared to the $\mathrm{CK}$ (Figure 3A). The $\mathrm{NaCl}$ treatment enhanced GmNCED9 expression at $6 \mathrm{~h}$ after imbibition, whereas $\mathrm{NaCl}$-induced GmNCED5 transcription was also detected at 3 and $6 \mathrm{~h}$ after sowing (Figure 3A). Higher GmAAO transcription levels were maintained, especially at $9 \mathrm{~h}$ after imbibition (Figure 3A). We next investigated the transcription levels of genes involved in the ABA signaling pathway. Figure 3B shows 
A

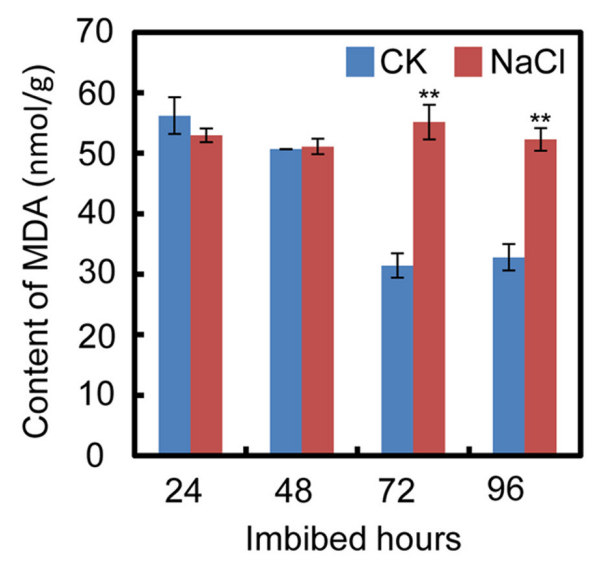

C

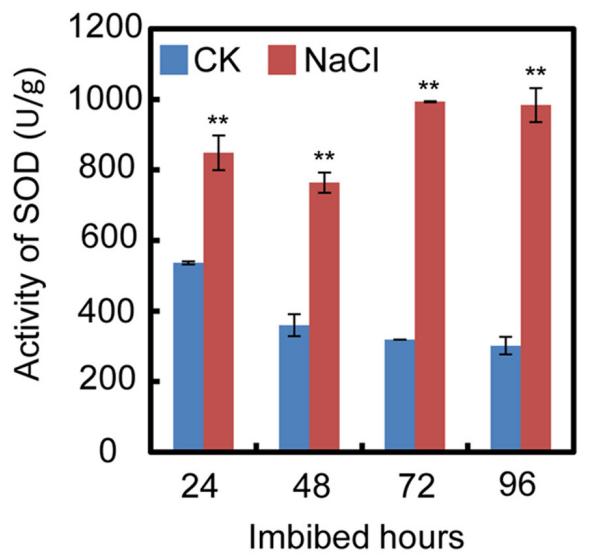

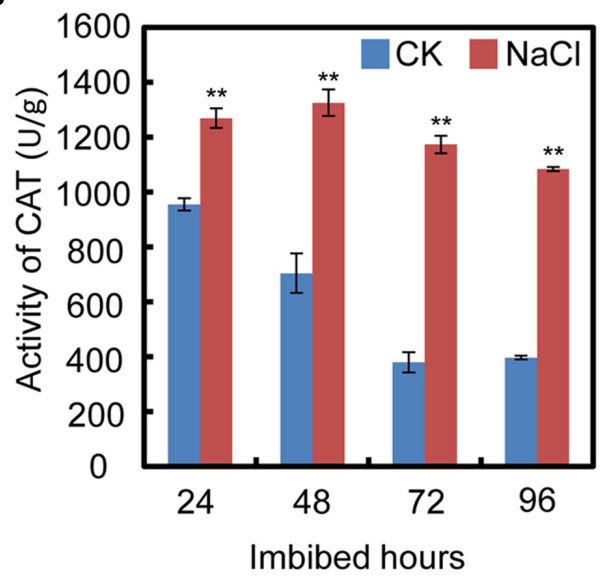

D

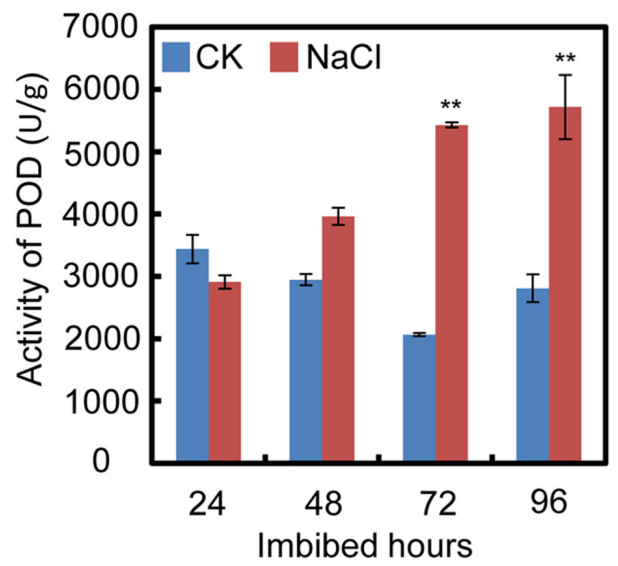

FIGURE 2 | Quantification of MDA (malondialdehyde) content, activities of superoxide dismutase (SOD), catalase (CAT), and peroxidase (POD) during soybean seed germination after $\mathrm{NaCl}$ application. (A) Effect of $\mathrm{NaCl}$ on change of MDA content during seed imbibition. (B-D) Activities of CAT, SOD, and POD after exogenous $\mathrm{NaCl}$ treatment during soybean seed germination. Soybean cultivar ND12 seeds were employed and the concentration of NaCl used was 150 mM. Student's $t$-test assay was employed for statistical analysis, and ** difference is significant at the 0.01 level.

that the exogenous $\mathrm{NaCl}$ application considerably enhanced ABA signaling by increasing $G m A B I 4$ and $G m A B I 5$ transcription because $G m A B I 4$ and $G m A B I 5$ are key positive regulators in the ABA signaling pathway (Shu et al., 2016b). Taken together, the transcription pattern analysis revealed that $\mathrm{ABA}$ content and signaling were possibly enhanced by exogenous $\mathrm{NaCl}$ treatment during soybean seed germination.

Subsequently, we further examined the expression pattern of the key genes involved in GA biogenesis and the signaling pathways. The qRT-PCR assay showed that after $\mathrm{NaCl}$ treatment the level of GA biosynthesis genes GmGA3ox1 and GmKAO decreased, especially at $9 \mathrm{~h}$ after sowing, compared to the CK (Figure 3C). On the other hand, GA inactive gene GmGA20x8 expression increased during seed imbibition (Figure 3D). Furthermore, GmRGL transcription, a gene that belongs to the DELLA family and represses seed coat rupture during seed germination (Piskurewicz and LopezMolina, 2009), was up-regulated considerably during imbibition after NaCl-treatment (Figure 3E). Taken together, these analyses revealed that exogenous $\mathrm{NaCl}$ probably negatively regulated GA biogenesis and signaling during soybean seed germination.

The qRT-PCR data described above hinted us that $\mathrm{NaCl}$ may mediate $\mathrm{ABA}$ and GA biogenesis by regulating the expression of the metabolic genes for both phytohormones. Consequently, the endogenous $\mathrm{ABA}$ and active GA levels during imbibition were quantified. The results indicated that $\mathrm{NaCl}$ significantly decreased active $\mathrm{GA}_{1}, \mathrm{GA}_{3}$, and $\mathrm{GA}_{4}$ levels (Figures $4 \mathrm{~A}-\mathrm{C}$ ). In contrast, the $\mathrm{ABA}$ content in $\mathrm{NaCl}$-treated soybean seed during imbibition remarkably increased (Figure 4D), which meant that the $\mathrm{GA}_{1} / \mathrm{ABA}, \mathrm{GA}_{3} / \mathrm{ABA}$, and $\mathrm{GA}_{4} / \mathrm{ABA}$ ratios were down-regulated (Figure $4 \mathrm{E}$ ). The active GA/ABA ratio is a key factor during seed germination (Finkelstein et al., 2008; Shu et al., 2016a,b). Therefore, the measurement of both ABA and GA supported the transcription analysis and the phenotype description. Altogether, all the results suggest that exogenous $\mathrm{NaCl}$ treatment positively regulates ABA biogenesis, but negatively mediates GA biosynthesis. 


\section{A}

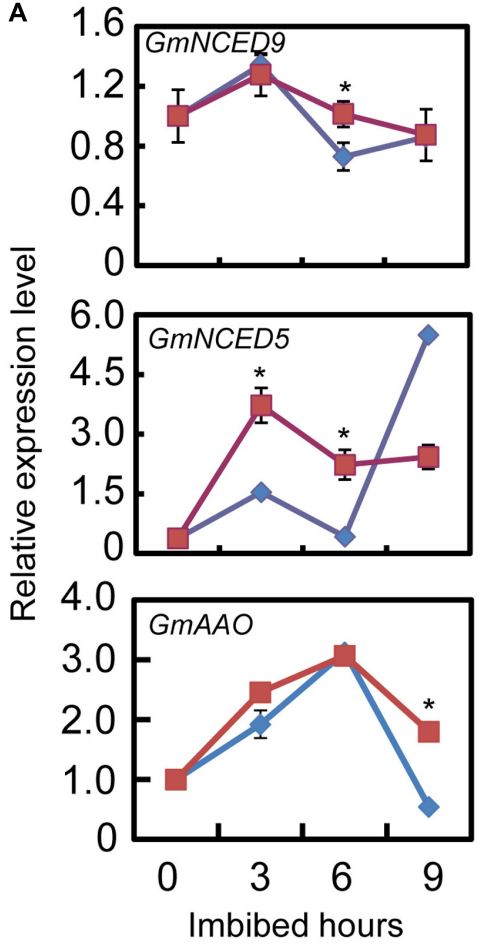

B

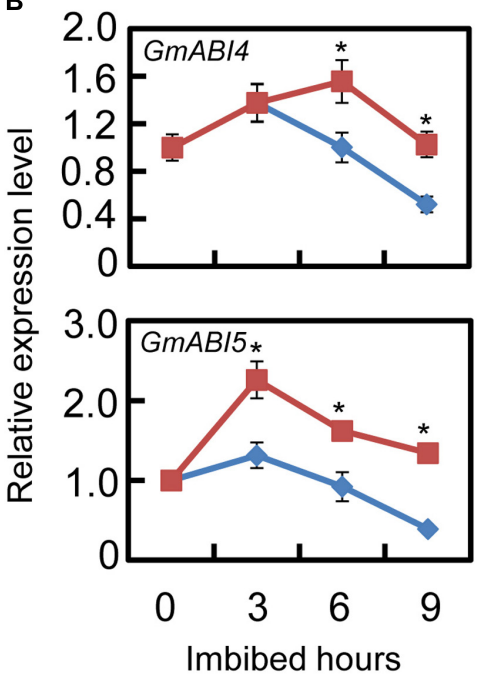

C

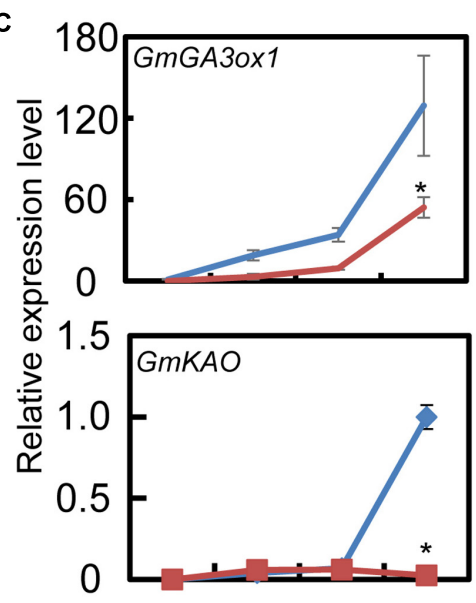

D

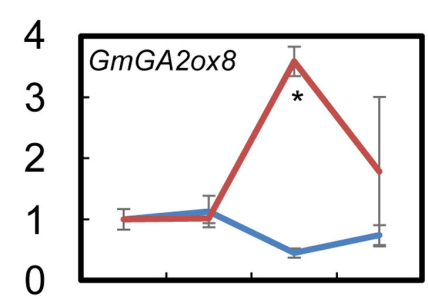

E

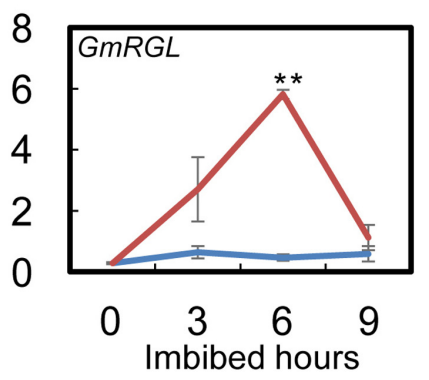

- CK

$-\mathrm{NaCl}$

FIGURE 3 | Gene transcription pattern analysis during the course of seed imbibition. Soybean cultivar ND12 dry seeds and imbibed seeds $(0,3,6,9 \mathrm{~h}$ after imbibition) were used for total RNA extraction. Three biological replications were performed. (A) Abscisic acid (ABA) biosynthesis genes, GmNCED9, GmNCED5, and GmAAO. (B) ABA signaling positive regulator genes, GmAB/5 and GmAB/4. (C) Gibberellin (GA) biosynthesis genes, GmGA3ox1 and GmKAO. (D) GA inactivate gene, GmGA2ox8. (E) negative regulator gene in GA signaling transduction pathway, GmRGL. Three replications were performed and similar results were obtained. The concentration of $\mathrm{NaCl}$ used was $150 \mathrm{mM}$. Student's $t$-test assay was employed for statistical analysis, and asterisks indicate statistically significant differences from CK at different time points $\left(* P<0.05 ;{ }^{* *} P<0.01\right)$. Primer pairs of the marker genes are listed in Supplementary Table S1.

\section{FLUN Partially Rescues the Delayed-Germination Phenotype of $\mathrm{NaCl}$-Treated Seeds}

To further confirm that $\mathrm{NaCl}$ enhances ABA biogenesis while impairs GA biogenesis during soybean seed germination, we next tested the responsiveness of soybean seeds to FLUN, an
ABA biosynthesis inhibitor, and paclobutrazol (PAC), a GA biosynthesis inhibitor, during seed imbibition.

We also investigated the effect of the FLUN and PAC treatments on soybean seed germination. The results showed that FLUN promotes soybean seed germination, whereas PAC delays imbibition and germination (Figures 5A,B). The effects on post-germination growth parameters, such as radicle 
A

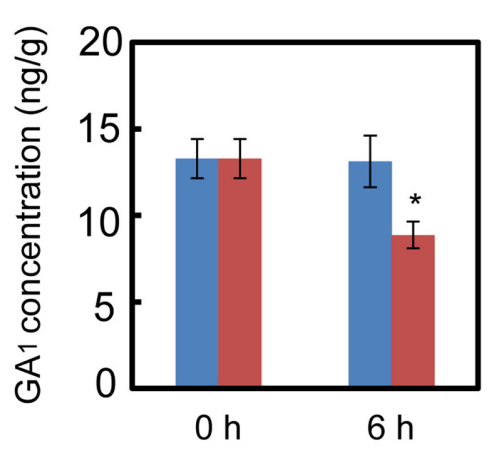

C

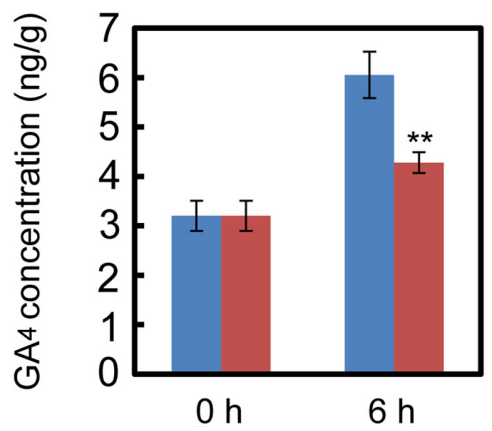

B

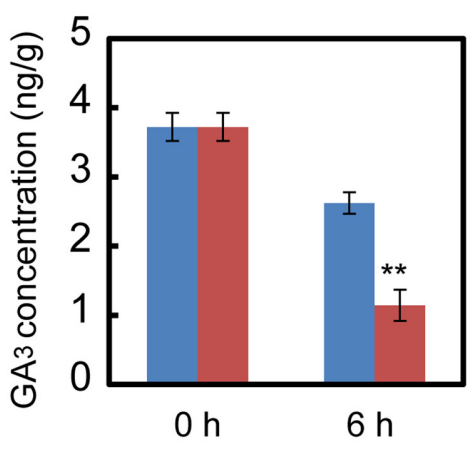

D

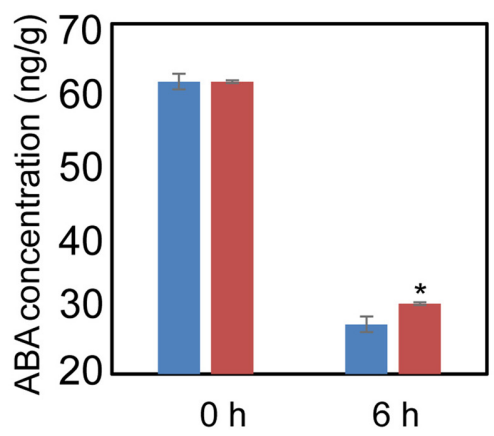

E

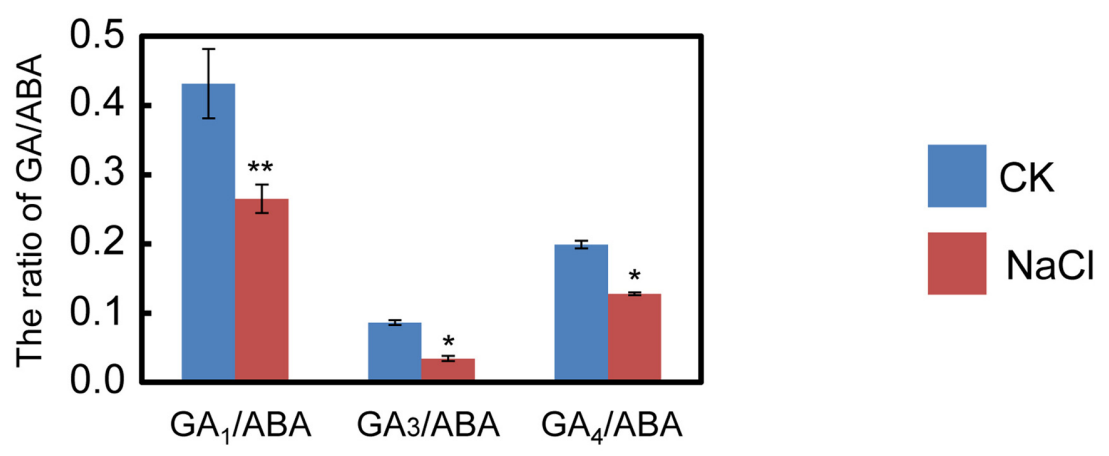

FIGURE 4 | $\mathrm{NaCl}$ decreases the ratios between active $\mathrm{GA}$ and $\mathrm{ABA}$, including $\mathrm{GA}_{1} / \mathrm{ABA}, \mathrm{GA}_{3} / \mathrm{ABA}$, and $\mathrm{GA} 4 / \mathrm{ABA}$. Soybean seeds were incubated at $25^{\circ} \mathrm{C}$ and treated with $\mathrm{NaCl}$. Equivalent ultrapure water was added as control (CK). Dry seeds and 6-h imbibed seeds were used to determine the concentration of endogenous active $\mathrm{GA}_{1}, \mathrm{GA}_{3}$, and $\mathrm{GA}_{4}$. The results showed that $\mathrm{NaCl}$ treatment decreases active $\mathrm{GA}_{1} \mathbf{( A )}, \mathrm{GA}_{3} \mathbf{( B )}$, and $\mathrm{GA}_{4}$ (C), while $A B A$ content was increased after $\mathrm{NaCl}$ application (D). The ratios of $\mathrm{GA}_{1} / \mathrm{ABA}, \mathrm{GA}_{3} / \mathrm{ABA}$, and $\mathrm{GA}_{4} / \mathrm{ABA}$ (E) were also shown. The concentration of $\mathrm{NaCl}$ used was $150 \mathrm{mM}$. Student's $t$-test assay was employed for statistical analysis, and * difference is significant at the 0.05 level, ${ }^{* *}$ difference is significant at the 0.01 level.

length (Figure 5C), were also similar to the germination results. The $\mathrm{NaCl}$-treatment clearly promotes ABA biosynthesis during soybean seed germination, and FLUN blocks the ABA biosynthesis pathway. Therefore, we hypothesized that FLUN may be able to rescue the delayed-germination phenotype caused by enhanced ABA biogenesis. The germination analysis showed that FLUN could partially restore the delayed-germination phenotype seen when soybean seeds are treated with $\mathrm{NaCl}$ (Figures 6A,B). As shown in Figure 6B, although the seed germination rate of $\mathrm{NaCl}$ treatment was similar to $\mathrm{NaCl}+\mathrm{FLUN}$ treatment within $24 \mathrm{~h}$ imbibition, the germination rate of $\mathrm{NaCl}+\mathrm{FLUN}$ was higher than that of $\mathrm{NaCl}$, but lower than that of CK between 36 to $60 \mathrm{~h}$ of imbibition (Figures 6B). This indicates that exogenous application of FLUN partially rescued salt stress inhibition of seed germination, which was also observed in Figure 6C based on radicle length. In other words, some other factors might be involved in salt stress-induced delay of seed germination (Figures 6C). On the other hand, we also found that $\mathrm{NaCl}+\mathrm{PAC}$ mimics the inhibition effect caused by $\mathrm{NaCl}$ treatment (Figures 7A,B), and the post-germinative growth parameters further supported this (Figure 7C). Taken together, these results demonstrated that $\mathrm{NaCl}$ delays the soybean seed germination process by promoting ABA biosynthesis while impairing GA biosynthesis. 


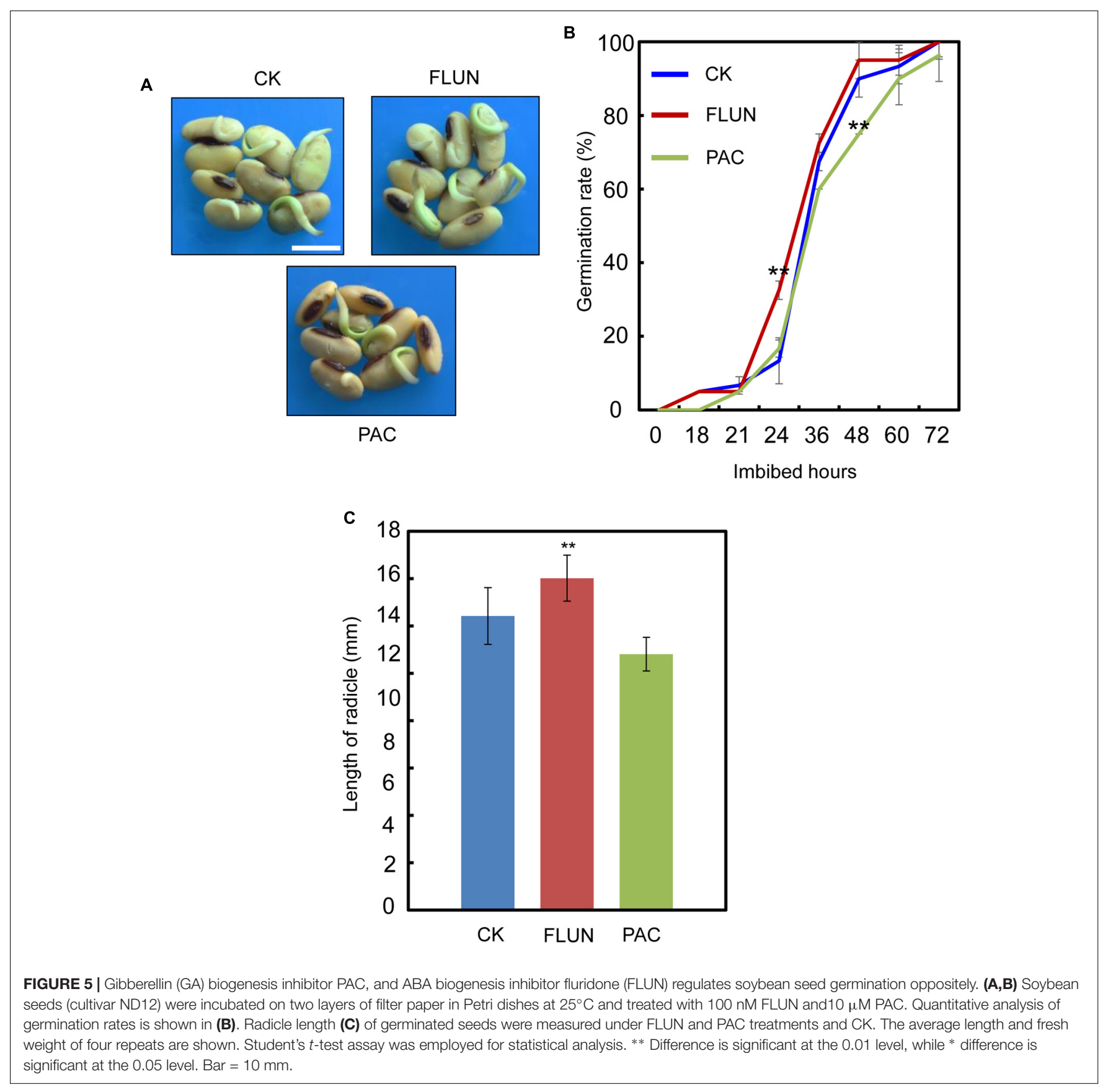

\section{DISCUSSION}

The large tracts of saline land that exist worldwide significantly constrain the development of sustainable agriculture, and on the other hand, they could also be used to improve food security after reclamation. However, the modification of salt-affected soils is very expensive and time-consuming. Consequently, increased plant salt resistance during different growth stages may provide a lower cost alternative for modern agriculture. Therefore, potential plant growth regulators should be explored further. In this study, we dissected the mechanisms through which salt repress soybean seed germination, and further showed that FLUN might be a potential plant growth regulator that could be used to promote soybean seed germination under salinity stress.

It is well-known that salt inhibits soybean seed germination and post-germinative growth, which eventually leads to decreases in yield (Hamayun et al., 2015). Previous investigations and the present study showed that $\mathrm{NaCl}$ treatment caused cellular oxidative stress (Figure 2; Liang et al., 2003; Zhu, 2016; Farhangi-Abriz and Torabian, 2017), and the level of cellular oxidative pressure is further associated with the activity of seed germination (Ma et al., 2017). In the past decade, soybean salt 


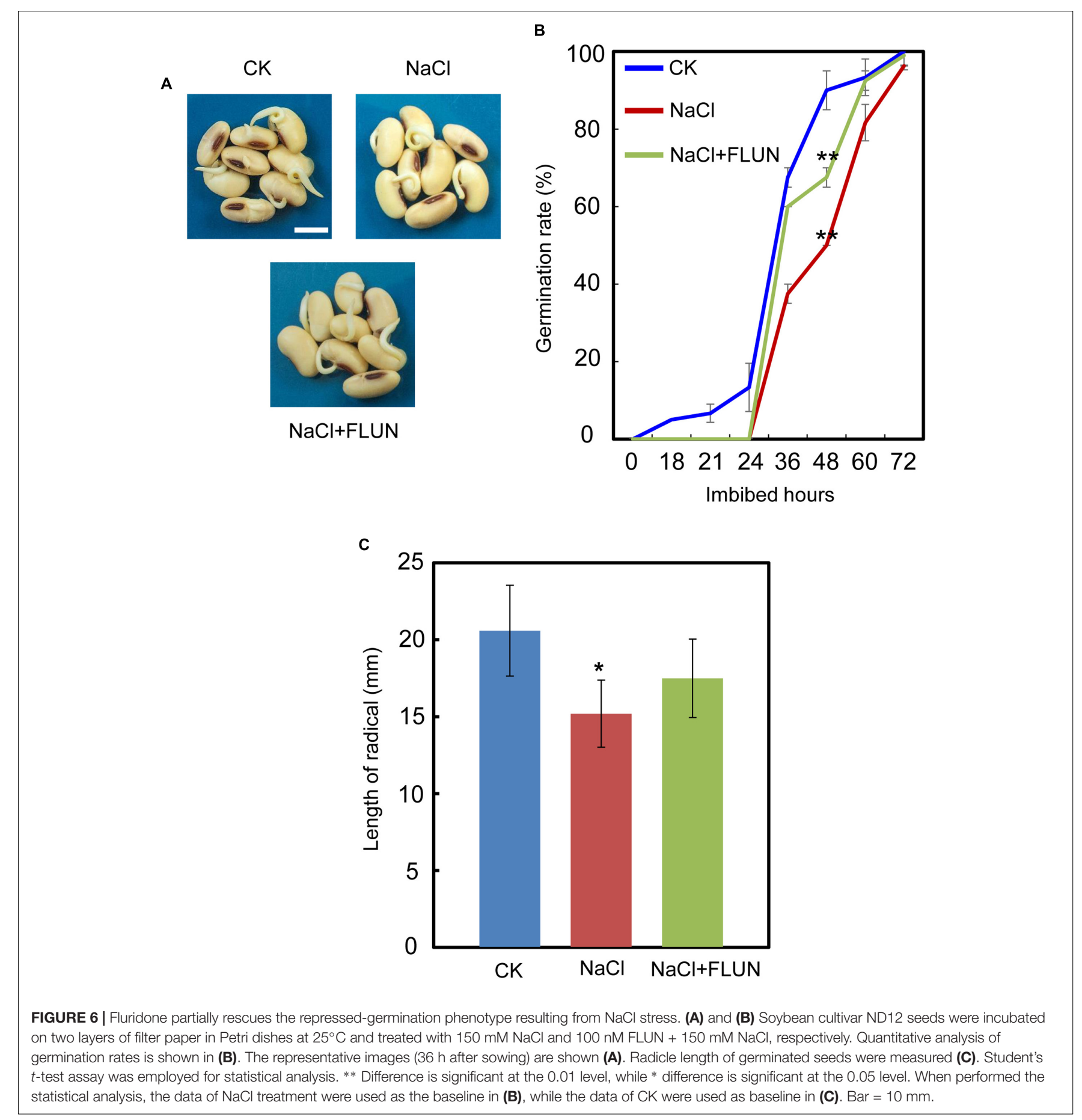

tolerance-related quantitative trait loci and some key proteins have been identified over the past few decades (Xu et al., 2011; Guan et al., 2014; Kan et al., 2015). However, the detailed molecular mechanisms underlying the inhibition-effect of salt on soybean seed germination and post-germinative growth are not fully understood, especially the relationship between salt effects and the ABA and GA pathways. In this study, the seed germination phenotype description (Figure $\mathbf{1}$ and Supplementary Figure S1), the biochemical analysis (Figure 2), the gene transcription pattern analysis (Figure 3), and the phytohormones measurement results (Figure 4) all demonstrated that $\mathrm{NaCl}$ stress positively regulated $\mathrm{ABA}$ biogenesis, but negatively mediated the GA biosynthesis pathways. This led to a decrease in the $G A$ and $A B A$ ratios (including $G_{1} / A B A$, $\mathrm{GA}_{3} / \mathrm{ABA}$, and $\left.\mathrm{GA}_{4} / \mathrm{ABA}\right)$. Importantly, we further have shown that FLUN might be a potential plant growth regulator that could promote soybean seed germination under salinity stress (Figure 6). 

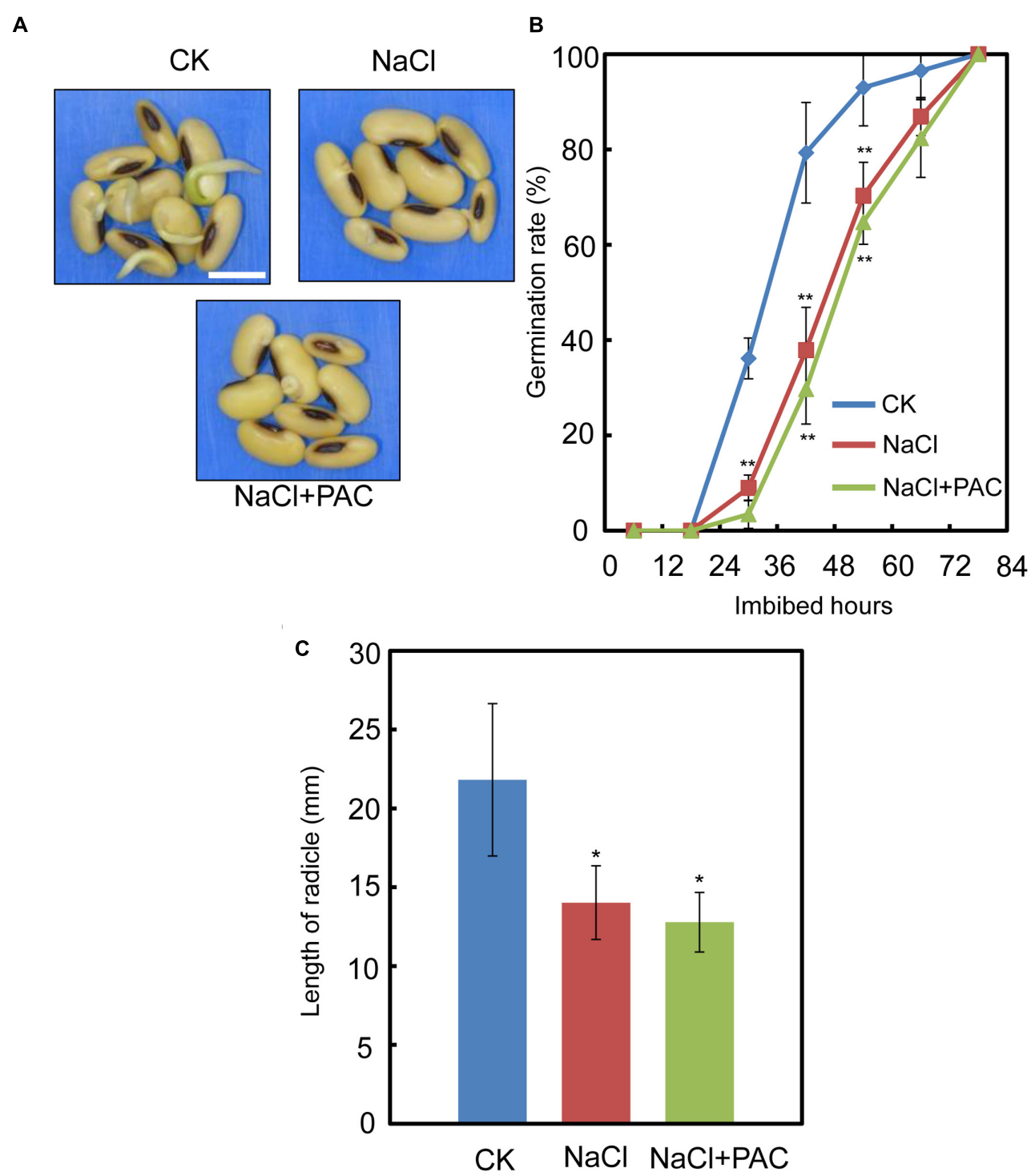

FIGURE 7 | The effect of PAC+NaCl combination treatment on soybean seed germination, Soybean cultivar ND12 seeds were used. (A-B) Soybean seeds were incubated on two layers of filter paper in Petri dishes at $25^{\circ} \mathrm{C}$ and treated with $150 \mathrm{mM} \mathrm{NaCl}$ and $100 \mathrm{nM} \mathrm{PAC}+150 \mathrm{mM}$ NaCl, respectively. Quantitative analysis of germination rates is shown in (B). The representative images (36 h after sowing) are shown (A). Radicle length of germinated seeds were measured (C). The CK data were used as baseline when performed the statistical analysis. Student's $t$-test assay was employed for statistical analysis. ${ }^{* *}$ Difference is significant at the 0.01 level, while * difference is significant at the 0.05 level. Bar $=10 \mathrm{~mm}$.

FLUN blocks ABA biosynthesis and disrupts plant photosynthesis (Stetsenko et al., 2015). It is also an aquatic herbicide that is usually used to control invasive plants (Gamble and Mullet, 1986; Sun et al., 2012). However, recent studies have revealed that FLUN is also involved in other processes, such as the regulation of plant drought stresses responses, plant development control, and even human disease control. It is well known that both heavy metals (including $\mathrm{Cu}^{2+}, \mathrm{Cd}^{2+}$, and $\mathrm{Hg}^{2+}$ ) and heat stress stop maize seed germination, but FLUN can significantly alleviate thermodormancy and rescue the delayed-germination phenotype caused by heavy metals (Deng et al., 2016). Furthermore, applying FLUN to tobacco leaves can promote NtEXGT expression and further increases plant drought resistance (Kuluev et al., 2017). It has also been recently demonstrated that FLUN stimulated Vellozia sp. seed germination in the dark (Vieira et al., 2017). Furthermore, FLUN has potential as a candidate drug for the treatment of acute neosporosis in vivo (Ybanez et al., 2016) and as a new anti-inflammatory drug (Magnone et al., 2013). These recent studies have demonstrated that FLUN possesses many different biological functions in both plants and animals.

Salinity inhibits soybean development across the whole lifecycle, which finally leads to decreased yields. Seed germination and emergence in the field are key crop yield determinants. 
However, large parts of the world are covered in saline soil, which significantly limits soybean seed germination and yield. Therefore, enhancing soybean seed germination under salt stress conditions will be of major benefit to agriculture worldwide. In this study, we showed that applying FLUN can rescue the delayed-germination phenotype caused by $\mathrm{NaCl}$ treatment. Consequently, FLUN can be a potential plant growth regulator that could be used to promote soybean seed germination under salt stress. Last but not least, it is noted that $\mathrm{NaCl}$ treatment caused oxidative stress in soybean seed cells (Figure 2), thus it is valuable to test whether and how FLUN enhances soybean seed germination under salt stress through activation of the cellular antioxidant systems.

\section{MATERIALS AND METHODS}

\section{Plant Materials and Growth Condition}

Soybean cultivars employed in the present investigation were Hedou-19 (HD-19), Nandou-12 (ND-12) and C-103. HD-19 and ND-12 (yellow seed coat in color) and C-103 (black seed coat in color) are the prevailing soybean cultivars in Southwestern China, and are breeded by Nanchong Academy of Agricultural Sciences, Sichuan Province, China. These three genotypes are distinct regards to the genetic background. These variates were grown in Science and Technology Campus, Sichuan Agricultural University, and were harvested at the same time. The elite soybean seeds were chosen for further investigation.

\section{Seed Germination Phenotypic Analysis}

For each petri dishes, 20 soybean seeds were incubated on two layers of medium-speed qualitative filter papers in Petri Dishes (diameter is $9 \mathrm{~cm}$ ). Then, $11 \mathrm{~mL}$ distilled water, $\mathrm{NaCl}$ (at $150 \mathrm{mM}$ ), $100 \mathrm{nM}$ FLUN or $10 \mu \mathrm{M}$ paclobutrazol (PAC) were add to each plate according to the experiment requirements. Four replications (Petri Dishe) were performed. The plates were incubated at $25^{\circ} \mathrm{C}$ in incubator (Sanyo Versatile Environmental Teat Chamber MLR-350H). Germination rates were considered when the radicle broke through the seed coat. The germination percentages were counted at with time-course analysis.

After $60 \mathrm{~h}$ of imbibition, the radicles will be cut off, and the length and fresh weight of radicles per 20 seeds were measured. The Image $\mathrm{J}$ software was employed to measure the length of radicles. For each germination test, three experimental replications were performed. The average germination percentage \pm SE (standard error) of triplicate experiments was calculated. $\mathrm{NaCl}$ (product number 7647-14-5), FLUN (product number 45511), and PAC (product number 33371) were ordered from Sigma-Aldrich Company Ltd., United States.

\section{Quantification of Activities of SOD, CAT, and POD and MDA Content}

After $\mathrm{NaCl}$ treatment, MDA content and the activities of SOD, CAT, and POD were detected during soybean seed germination processes with time-course pattern. The method published elsewhere were employed for the quantification (Yang et al., 2010).

\section{Gene Expression Analysis}

Imbibition seeds were collected at different time points after sowing and frozen in liquid nitrogen quickly. Total RNA preparation, first-strand cDNA synthesis and qRT-PCR assay were performed as our previously described (Shu et al., 2013). Quantitative PCR was performed using the SsoFast ${ }^{\mathrm{TM}}$ EvaGreen Supermix (Bio-Rad). Each $10 \mu \mathrm{L}$ reaction comprised $2 \mu \mathrm{L}$ template, $5 \mu \mathrm{L}$ SsoFast ${ }^{\mathrm{TM}}$ EvaGreen Supermix, $0.5 \mu \mathrm{L}$ $(10 \mu \mathrm{M})$ of each primer and $2 \mu \mathrm{L}$ Dnase-free $\mathrm{ddH}_{2} \mathrm{O}$. The transcription pattern of genes involved in ABA/GA biosynthesis and signaling transduction pathways including GmNCED9, GmNCED5, GmAAO, GmABI4, GmABI5, and GmGA3ox1, $G m K A O, G m G A 2 o x 8$, and $G m R G L$ were investigated. Three biological replicates were performed for each experiment. Primer sequences for qRT-PCR are shown in Supplemental Table S1.

\section{Quantification of ABA in Soybean Seeds}

For analysis of ABA content in soybean seeds, the previously protocol we used (Shu et al., 2013) were employed in this study. Firstly, the seeds were ground to powder in liquid nitrogen, and $300 \mathrm{mg}$ of seeds powder was homogenized and extracted for $24 \mathrm{~h}$ in methanol containing D6-ABA (OIChemIm Co. Ltd.) as an internal standard. Purification was performed with an Oasis Max solid phase extract cartridge (Waters) and eluted with 5\% formic acid in methanol. Subsequently, the elution was dried and reconstituted, and it was then injected into a liquid chromatography-tandem mass spectrometry system consisting of an Acquity ultra performance liquid chromatograph (Acquity UPLC; Waters) and a triple quadruple tandem mass spectrometer (Quattro Premier XE; Waters). Three biological replications were performed.

\section{Quantification of Endogenous Gibberellins}

The endogenous gibberellins were determined according to our method described previously (Chen et al., 2011). Soybean seeds (400 mg) were frozen in liquid nitrogen, ground to fine powder, and extracted with $80 \%(\mathrm{v} / \mathrm{v})$ methanol. GA $\mathrm{d}_{2}$ isotope standards were added to plant samples before grinding. The crude extracts were purified by reversed-phase solid-phase extraction, ethyl ether extraction, and derivatization. The resulting mixture was injected into capillary electrophoresis-mass spectrometry (CE-MS) for quantitative analysis. Three biological replications were performed.

\section{Statistical Analysis}

The data including germination rates, fresh weight and radicle length of germinated seeds, gene expression data, and phytohormones quantification results were analyzed using 
Student's $t$-test. Different baselines were employed according to different requirements, and the detailed information was presented in the figure legends.

\section{AUTHOR CONTRIBUTIONS}

KS designed the research. YQ, FC, YM, XL, HS, WZ, JDi, JDu, JL, FY, QW, WL, TY, XW, and YF performed the experiments. KS and $\mathrm{WY}$ analyzed the data and wrote the manuscript.

\section{FUNDING}

This work was supported by Funding of Department of Education Sichuan Province (16ZB0040), National Key Research and Development Program of China (2017YFD0201306), and China Postdoctoral Science Foundation funded project (2014M552377 and 2016T90868).

\section{REFERENCES}

Chen, M. L., Huang, Y. Q., Liu, J. Q., Yuan, B. F., and Feng, Y. Q. (2011). Highly sensitive profiling assay of acidic plant hormones using a novel mass probe by capillary electrophoresis-time of flight-mass spectrometry. J. Chromatogr. $B$ Analyt. Technol. Biomed. Life Sci. 879, 938-944. doi: 10.1016/j.jchromb.2011. 03.003

Deng, B., Yang, K., Zhang, Y., and Li, Z. (2016). Can heavy metal pollution defend seed germination against heat stress? Effect of heavy metals $\left(\mathrm{Cu}^{2+}, \mathrm{Cd}^{2+}\right.$ and $\mathrm{Hg}^{2+}$ ) on maize seed germination under high temperature. Environ. Pollut. 216, 46-52. doi: 10.1016/j.envpol.2016.05.050

Farhangi-Abriz, S., and Torabian, S. (2017) Antioxidant enzyme and osmotic adjustment changes in bean seedlings as affected by biochar under salt stress. Ecotoxicol. Environ. Saf. 137, 64-70. doi: 10.1016/j.ecoenv.2016.11.029

Finkelstein, R., Reeves, W., Ariizumi, T., and Steber, C. (2008). Molecular aspects of seed dormancy. Annu. Rev. Plant Biol. 59, 387-415. doi: 10.1146/annurev. arplant.59.032607.092740

Frey, A., Audran, C., Marin, E., Sotta, B., and Marion-Poll, A. (1999). Engineering seed dormancy by the modification of zeaxanthin epoxidase gene expression. Plant Mol. Biol. 39, 1267-1274. doi: 10.1023/A:100614502 5631

Frey, A., Effroy, D., Lefebvre, V., Seo, M., Perreau, F., Berger, A., et al. (2012). Epoxycarotenoid cleavage by NCED5 fine-tunes ABA accumulation and affects seed dormancy and drought tolerance with other NCED family members. Plant J. 70, 501-512. doi: 10.1111/j.1365-313X.2011.04887.x

Galle, A., Csiszar, J., Benyo, D., Laskay, G., Leviczky, T., Erdei, L., et al. (2013). Isohydric and anisohydric strategies of wheat genotypes under osmotic stress: biosynthesis and function of ABA in stress responses. J. Plant Physiol. 170, 1389-1399. doi: 10.1016/j.jplph.2013.04.010

Gamble, P. E., and Mullet, J. E. (1986). Inhibition of carotenoid accumulation and abscisic acid biosynthesis in fluridone-treated dark-grown barley. Eur. J. Biochem. 160, 117-121. doi: 10.1111/j.1432-1033.1986.tb09947.x

Gonzalez-Guzman, M., Apostolova, N., Belles, J. M., Barrero, J. M., Piqueras, P., Ponce, M. R., et al. (2002). The short-chain alcohol dehydrogenase ABA2 catalyzes the conversion of xanthoxin to abscisic aldehyde. Plant Cell 14, 1833-1846. doi: 10.1105/tpc.002477

Graeber, K., Nakabayashi, K., Miatton, E., Leubner-Metzger, G., and Soppe, W. J. (2012). Molecular mechanisms of seed dormancy. Plant Cell Environ. 35, 1769-1786. doi: 10.1111/j.1365-3040.2012.02542.x

Guan, R., Qu, Y., Guo, Y., Yu, L., Liu, Y., Jiang, J., et al. (2014). Salinity tolerance in soybean is modulated by natural variation in GmSALT3. Plant J. 80, 937-950. doi: $10.1111 /$ tpj.12695

Hamayun, M., Hussain, A., Khan, S. A., Irshad, M., Khan, A. L., Waqas, M., et al. (2015). Kinetin modulates physio-hormonal attributes and isoflavone contents

\section{ACKNOWLEDGMENT}

We thank Ms. Chunyan Liu and Liang Yu (Sichuan Agricultural University) for the technical assistance.

\section{SUPPLEMENTARY MATERIAL}

The Supplementary Material for this article can be found online at: http://journal.frontiersin.org/article/10.3389/fpls.2017.01372/ full\#supplementary-material

FIGURE S1 | $\mathrm{NaCl}$ inhibits soybean seed germination. Cultivars $\mathrm{C}-103$ seeds was incubated on two layers of filter paper in Petri dishes. The concentration of $\mathrm{NaCl}$ used was $150 \mathrm{mM}$, and the equivalent ultrapure water was employed as control (CK). (A) The representative images (36 h after sowing) are shown. (B) Quantitative analysis of germination rates is shown. (C,D) Radicle length and fresh weight of germinated soybean seeds were measured. Bar $=10 \mathrm{~mm}$. The average percentages of four repeats \pm standard error were shown. Student's $t$-test assay was employed for statistical analysis. ** Difference is significant at the 0.01 level.

of Soybean grown under salinity stress. Front. Plant Sci. 6:377. doi: 10.3389/fpls. 2015.00377

Hanin, M., Ebel, C., Ngom, M., Laplaze, L., and Masmoudi, K. (2016). New insights on plant salt tolerance mechanisms and their potential use for breeding. Front. Plant Sci. 7:1787. doi: 10.3389/fpls.2016.01787

Hasegawa, P. M., Bressan, R. A., Zhu, J. K., and Bohnert, H. J. (2000). Plant cellular and molecular responses to high salinity. Annu. Rev. Plant Physiol. Plant Mol. Biol. 51, 463-499. doi: 10.1146/annurev.arplant.51.1.463

Horvath, E., Csiszar, J., Galle, A., Poor, P., Szepesi, A., and Tari, I. (2015). Hardening with salicylic acid induces concentration-dependent changes in abscisic acid biosynthesis of tomato under salt stress. J. Plant Physiol. 183, 54-63. doi: 10.1016/j.jplph.2015.05.010

Kan, G., Ning, L., Li, Y., Hu, Z., Zhang, W., He, X., et al. (2016). Identification of novel loci for salt stress at the seed germination stage in soybean. Breed. Sci. 66, 530-541. doi: 10.1270/jsbbs.15147

Kan, G., Zhang, W., Yang, W., Ma, D., Zhang, D., Hao, D., et al. (2015). Association mapping of soybean seed germination under salt stress. Mol. Genet. Genomics 290, 2147-2162. doi: 10.1007/s00438-015-1066-y

Koornneef, M., Hanhart, C. J., Hilhorst, H. W., and Karssen, C. M. (1989). In vivo inhibition of seed development and reserve protein accumulation in recombinants of abscisic acid biosynthesis and responsiveness mutants in Arabidopsis thaliana. Plant Physiol. 90, 463-469. doi: 10.1104/pp.90. 2.463

Kuluev, B., Mikhaylova, E., Berezhneva, Z., Nikonorov, Y., Postrigan, B., Kudoyarova, G., et al. (2017). Expression profiles and hormonal regulation of tobacco NtEXGT gene and its involvement in abiotic stress response. Plant Physiol. Biochem. 111, 203-215. doi: 10.1016/j.plaphy.2016. 12.005

Lee, S., Cheng, H., King, K. E., Wang, W., He, Y., Hussain, A., et al. (2002). Gibberellin regulates Arabidopsis seed germination via RGL2, a GAI/RGA-like gene whose expression is up-regulated following imbibition. Genes Dev. 16, 646-658. doi: 10.1101/gad.969002

Li, W., Wang, T., Zhang, Y., and Li, Y. (2016). Overexpression of soybean miR172c confers tolerance to water deficit and salt stress, but increases ABA sensitivity in transgenic Arabidopsis thaliana. J. Exp. Bot. 67, 175-194. doi: 10.1093/jxb/ erv 450

Li, W., Yamaguchi, S., Khan, M. A., An, P., Liu, X., and Tran, L. S. (2015). Roles of gibberellins and abscisic acid in regulating germination of Suaeda salsa dimorphic seeds under salt stress. Front. Plant Sci. 6:1235. doi: 10.3389/fpls. 2015.01235

Liang, Y. C., Chen, Q., Liu, Q., Zhang, W. H., and Ding, R. X. (2003). Exogenous silicon $(\mathrm{Si})$ increases antioxidant enzyme activity and reduces lipid peroxidation in roots of salt-stressed barley (Hordeum vulgare L.). J. Plant Physiol. 160, 1157-1164. doi: 10.1078/0176-1617-01065 
Liao, Y., Zhang, J. S., Chen, S. Y., and Zhang, W. K. (2008a). Role of soybean GmbZIP132 under abscisic acid and salt stresses. J. Integr. Plant Biol. 50, 221-230. doi: 10.1111/j.1744-7909.2007.00593.x

Liao, Y., Zou, H. F., Wang, H. W., Zhang, W. K., Ma, B., Zhang, J. S., et al. (2008b). Soybean GmMYB76, GmMYB92, and GmMYB177 genes confer stress tolerance in transgenic Arabidopsis plants. Cell Res. 18, 1047-1060. doi: 10.1038/cr. 2008.280

Lin, P. C., Hwang, S. G., Endo, A., Okamoto, M., Koshiba, T., and Cheng, W. H. (2007). Ectopic expression of ABSCISIC ACID 2/GLUCOSE INSENSITIVE 1 in Arabidopsis promotes seed dormancy and stress tolerance. Plant Physiol. 143, 745-758. doi: 10.1104/pp.106.084103

Liu, Y., Yu, L., Qu, Y., Chen, J., Liu, X., Hong, H., et al. (2016). GmSALT3, which confers improved soybean salt tolerance in the field, increases leaf $\mathrm{Cl}$ - exclusion prior to $\mathrm{Na}^{+}$exclusion but does not improve early vigor under salinity. Front. Plant Sci. 7:1485. doi: 10.3389/fpls.2016.01485

Ma, Q., Kang, J., Long, R., Zhang, T., Xiong, J., Zhang, K., et al. (2017). Comparative proteomic analysis of alfalfa revealed new salt and drought stress-related factors involved in seed germination. Mol. Biol. Rep. 44, 261-272. doi: 10.1007/s11033017-4104-5

Magnone, M., Scarfi, S., Sturla, L., Guida, L., Cuzzocrea, S., Di Paola, R., et al. (2013). Fluridone as a new anti-inflammatory drug. Eur. J. Pharmacol. 720, 7-15. doi: 10.1016/j.ejphar.2013.10.058

Meng, Y., Chen, F., Shuai, H., Luo, X., Ding, J., Tang, S., et al. (2016). Karrikins delay soybean seed germination by mediating abscisic acid and gibberellin biogenesis under shaded conditions. Sci. Rep. 6:22073. doi: 10.1038/ srep 22073

Munns, R. (2002). Comparative physiology of salt and water stress. Plant Cell Environ. 25, 239-250. doi: 10.1046/j.0016-8025.2001.00808.x

Munns, R., and Tester, M. (2008). Mechanisms of salinity tolerance. Annu. Rev. Plant Biol. 59, 651-681. doi: 10.1146/annurev.arplant.59.032607.092911

Nee, G., Xiang, Y., and Soppe, W. J. (2016). The release of dormancy, a wake-up call for seeds to germinate. Curr. Opin. Plant Biol. 35, 8-14. doi: 10.1016/j.pbi. 2016.09.002

Piskurewicz, U., Jikumaru, Y., Kinoshita, N., Nambara, E., Kamiya, Y., and LopezMolina, L. (2008). The gibberellic acid signaling repressor RGL2 inhibits Arabidopsis seed germination by stimulating abscisic acid synthesis and ABI5 activity. Plant Cell 20, 2729-2745. doi: 10.1105/tpc.108.061515

Piskurewicz, U., and Lopez-Molina, L. (2009). The GA-signaling repressor RGL3 represses testa rupture in response to changes in GA and ABA levels. Plant Signal. Behav. 4, 63-65.

Seo, M., Hanada, A., Kuwahara, A., Endo, A., Okamoto, M., Yamauchi, Y., et al. (2006). Regulation of hormone metabolism in Arabidopsis seeds: phytochrome regulation of abscisic acid metabolism and abscisic acid regulation of gibberellin metabolism. Plant J. 48, 354-366. doi: 10.1111/j.1365-313X.2006.02881.x

Shakirova, F., Sakhabutdinova, A., Bezrukova, M., Fatkhutdinova, R., and Fatkhutdinova, D. (2003). Changes in the hormonal status of wheat seedlings induced by salicylic acid and salinity. Plant Sci. 164, 317-322. doi: 10.1016/ S0168-9452(02)00415-6

Shu, K., Chen, Q., Wu, Y., Liu, R., Zhang, H., Wang, P., et al. (2016a). ABI4 mediates antagonistic effects of abscisic acid and gibberellins at transcript and protein levels. Plant J. 85, 348-361. doi: 10.1111/tpj.13109

Shu, K., Liu, X. D., Xie, Q., and He, Z. H. (2016b). Two faces of one seed: hormonal regulation of dormancy and germination. Mol. Plant 9, 34-45. doi: 10.1016/j. molp.2015.08.010

Shu, K., Meng, Y. J., Shuai, H. W., Liu, W. G., Du, J. B., Liu, J., et al. (2015). Dormancy and germination: How does the crop seed decide? Plant Biol. 17, 1104-1112. doi: 10.1111/plb.12356

Shu, K., Zhang, H., Wang, S., Chen, M., Wu, Y., Tang, S., et al. (2013). ABI4 regulates primary seed dormancy by regulating the biogenesis of abscisic acid and gibberellins in Arabidopsis. PLoS Genet. 9:e1003577. doi: 10.1371/journal. pgen. 1003577
Stetsenko, L. A., Vedenicheva, N. P., Likhnevsky, R. V., and Kuznetsov, V. V. (2015). Influence of abscisic acid and fluridone on the content of phytohormones and polyamines and the level of oxidative stress in plants of Mesembryanthemum crystallinum L. under salinity. Izv. Akad. Nauk. Ser. Biol. 42, 134-144.

Sun, K., Gao, B., Ro, K. S., Novak, J. M., Wang, Z., Herbert, S., et al. (2012). Assessment of herbicide sorption by biochars and organic matter associated with soil and sediment. Environ. Pollut. 163, 167-173. doi: 10.1016/j.envpol. 2011.12.015

Teige, M., Scheikl, E., Eulgem, T., Doczi, R., Ichimura, K., Shinozaki, K., et al. (2004). The MKK2 pathway mediates cold and salt stress signaling in Arabidopsis. Mol. Cell 15, 141-152. doi: 10.1016/j.molcel.2004.06.023

Vieira, B. C., Bicalho, E. M., Munne-Bosch, S., and Garcia, Q. S. (2017). Abscisic acid regulates seed germination of Vellozia species in response to temperature. Plant Biol. 19, 211-216. doi: 10.1111/plb.12515

Wang, Y., Wang, L., Zou, Y., Chen, L., Cai, Z., Zhang, S., et al. (2014). Soybean miR172c targets the repressive AP2 transcription factor $\mathrm{NNC1}$ to activate ENOD40 expression and regulate nodule initiation. Plant Cell 26, 4782-4801. doi: $10.1105 /$ tpc.114.131607

Xiong, L., Lee, H., Ishitani, M., and Zhu, J. K. (2002). Regulation of osmotic stressresponsive gene expression by the LOS6/ABA1 locus in Arabidopsis. J. Biol. Chem. 277, 8588-8596. doi: 10.1074/jbc.M109275200

$\mathrm{Xu}, \mathrm{X}$., Fan, R., Zheng, R., Li, C., and Yu, D. (2011). Proteomic analysis of seed germination under salt stress in soybeans. J. Zhejiang Univ. Sci. B 12, 507-517. doi: 10.1631/jzus.B1100061

Yamauchi, Y., Takeda-Kamiya, N., Hanada, A., Ogawa, M., Kuwahara, A., Seo, M., et al. (2007). Contribution of gibberellin deactivation by AtGA2ox2 to the suppression of germination of dark-imbibed Arabidopsis thaliana seeds. Plant Cell Physiol. 48, 555-561. doi: 10.1093/pcp/pcm023

Yang, F., Wang, Y., and Miao, L. F. (2010). Comparative physiological and proteomic responses to drought stress in two poplar species originating from different altitudes. Physiol. Plant. 139, 388-400. doi: 10.1111/j.1399-3054.2010. 01375.x

Ybanez, R. H., Leesombun, A., Nishimura, M., Matsubara, R., Kojima, M., Sakakibara, H., et al. (2016). In vitro and in vivo effects of the phytohormone inhibitor fluridone against Neospora caninum infection. Parasitol. Int. 65, 319-322. doi: 10.1016/j.parint.2016.03.009

Zhang, W. J., Niu, Y., Bu, S. H., Li, M., Feng, J. Y., Zhang, J., et al. (2014). Epistatic association mapping for alkaline and salinity tolerance traits in the soybean germination stage. PLoS ONE 9:e84750. doi: 10.1371/journal.pone.008 4750

Zhang, Y., Lan, H., Shao, Q., Wang, R., Chen, H., Tang, H., et al. (2016). An A20/AN1-type zinc finger protein modulates gibberellins and abscisic acid contents and increases sensitivity to abiotic stress in rice (Oryza sativa). J. Exp. Bot. 67, 315-326. doi: 10.1093/jxb/erv464

Zhu, J. K. (2002). Salt and drought stress signal transduction in plants. Annu. Rev. Plant Biol. 53, 247-273. doi: 10.1146/annurev.arplant.53.091401.143329

Zhu, J. K. (2016). Abiotic stress signaling and responses in plants. Cell 167, 313-324. doi: 10.1016/j.cell.2016.08.029

Conflict of Interest Statement: The authors declare that the research was conducted in the absence of any commercial or financial relationships that could be construed as a potential conflict of interest.

Copyright (C) 2017 Shu, Qi, Chen, Meng, Luo, Shuai, Zhou, Ding, Du, Liu, Yang, Wang, Liu, Yong, Wang, Feng and Yang. This is an open-access article distributed under the terms of the Creative Commons Attribution License (CC BY). The use, distribution or reproduction in other forums is permitted, provided the original author(s) or licensor are credited and that the original publication in this journal is cited, in accordance with accepted academic practice. No use, distribution or reproduction is permitted which does not comply with these terms. 